\title{
Influence of Noninvasive Ventilation Protocol on Intubation Rates in Subjects With De Novo Respiratory Failure
}

\author{
Rémi Coudroy, Marie-Anne Hoppe, René Robert, Jean-Pierre Frat, and Arnaud W Thille
}

\begin{abstract}
BACKGROUND: The use of noninvasive ventilation (NIV) is debated in de novo respiratory failure. Prolonged sessions, using a dedicated NIV ventilator, with high PEEP levels could be associated with better outcomes than shorter sessions using an ICU ventilator, with low PEEP levels. We performed a systematic review of randomized controlled trials to test whether the incidence of intubation was influenced by the NIV protocol in subjects admitted to the ICU for de novo respiratory failure. METHODS: We selected randomized trials on NIV indexed in medical literature databases from their inception to April 2018. Pediatric studies, those performed outside of the ICU, trials with subjects on NIV for a reason other than de novo respiratory failure, and studies in which NIV protocol was not specified were excluded. Two authors independently extracted intubation rates and the NIV protocol (prolonged or short sessions, type of ventilator, and PEEP levels). RESULTS: Fourteen studies, which included 750 subjects treated with NIV for de novo respiratory failure in ICU, were analyzed. Overall intubation rate was $38 \%, 95 \%$ CI 31-45\% and was not influenced by prolonged NIV sessions or the type of ventilator. The 154 subjects treated with PEEP greater than the median overall PEEP $\left(6 \mathrm{~cm} \mathrm{H}_{2} \mathrm{O}\right)$ had a PEEP level of $8 \pm 2 \mathrm{~cm} \mathrm{H} \mathrm{H}_{2} \mathrm{O}$ and a pressure support level of $7 \pm 2 \mathrm{~cm} \mathrm{H}_{2} \mathrm{O}$. Their intubation rate was lower than the 293 subjects treated with lower PEEP levels (25\%, 95\% CI 15-37\% vs 43\%, 95\% CI 33-54\%, respectively, $P=.03$ ). Inclusion criteria were heterogeneous, and critical information on NIV application were frequently lacking. CONCLUSIONS: Except for high PEEP levels that might be associated with lower intubation rates, the protocol for carrying out NIV does not seem to influence intubation rate in patients with de novo respiratory failure. Key words: respiratory failure; ARDS; intensive care unit; noninvasive ventilation; endotracheal intubation; systematic review. [Respir Care 2020;65(4):525-534. @ 2020 Daedalus Enterprises]
\end{abstract}

\section{Introduction}

Noninvasive ventilation (NIV) is frequently used in the ICU to avoid intubation of patients with acute respiratory failure. ${ }^{1}$ It reduces intubation rates of patients with cardiogenic pulmonary edema ${ }^{2}$ or COPD exacerbation. ${ }^{3}$ How-

Drs Coudroy, Hoppe, Robert, Frat, and Thille are affiliated with Centre Hospitalier Universitaire de Poitiers, Service de Médecine Intensive Réanimation, Poitiers, France. Drs Coudroy, Robert, Frat, and Thille are affiliated with Institut National de la Santé et de la Recherche Médicale, Centre d'Investigation Clinique 1402, Groupe Acute Lung Injury and Ventilation (ALIVE), Poitiers, France. Drs Coudroy, Robert, Frat, and Thille are affiliated with Université de Poitiers, Faculté de Médecine et Pharmacie, Poitiers, France.

Dr Coudroy presented an e-poster at French Intensive Care Congress, 23-25th January 2019, Paris, France. ever, in patients with de novo respiratory failure, that is, without cardiogenic pulmonary edema and without underlying chronic lung disease, the beneficial effects of NIV

\footnotetext{
Dr Coudroy discloses relationships with MSD and Fisher \& Paykel. Dr Frat is discloses relationships with Fisher \& Paykel. Dr Thille discloses relationships with Fisher \& Paykel, Covidien, General Electrics, and Maquet-Getinge. The remaining authors have disclosed no conflicts of interest.
}

Supplementary material related to this paper is available at http:// www.rcjournal.com.

Correspondence: Rémi Coudroy MD, Médecine Intensive Réanimation, Centre Hospitalier Universitaire de Poitiers, 2 rue de la Milétrie, 86021, Poitiers, France. E-mail: r.coudroy@yahoo.fr.

DOI: $10.4187 /$ respcare. 07104 
are debatable and recent European and American clinical practice guidelines were unable to offer recommendations for NIV in this clinical setting. ${ }^{4}$ The rates of intubation are particularly high in patients with de novo respiratory failure, ranging from 30 to $60 \%$, and, although NIV may decrease the need for intubation compared with standard oxygen, no significant difference was found in terms of mortality by pooling all the randomized controlled trials. ${ }^{5-14}$ However, the protocol for applying NIV may have an impact on the risk of failure and, therefore, on intubation rates.

Several options have been proposed to improve NIV efficacy. Prolonged use of NIV may be more effective than shorter sessions. ${ }^{15}$ Dedicated NIV ventilators may be better tolerated than ICU ventilators, secondary to improved patient-ventilator asynchrony, ${ }^{16}$ which is a key factor for NIV success. ${ }^{1}$ Also, application of higher levels of PEEP could be more effective than lower PEEP levels by increasing oxygenation and alveolar recruitment, ${ }^{17}$ as is the case of patients with ARDS who are on mechanical ventilation. ${ }^{18}$ Because these hypotheses have been poorly investigated, we performed a systematic review of trials that involved subjects admitted to the ICU for de novo respiratory failure with the aim of comparing intubation rates according to the NIV protocol, including the abovementioned factors.

\section{Methods}

\section{Aims}

The primary outcome was intubation rates according to method of administration of NIV (prolonged vs shorter sessions). Secondary outcomes were intubation rates according to type of ventilator (dedicated NIV vs ICU ventilators) and level of PEEP according to the median value adjusted among selected studies (high PEEP levels if above the median vs low PEEP levels).

\section{Design}

Several meta-analyses compared NIV with control therapies for acute respiratory failure; however, none of these studies considered the protocol for applying NIV.19-21 Therefore, we decided to select randomized controlled trials in which subjects were allocated to receive NIV for de novo respiratory failure and to compare the incidence of NIV failure (intubation) across selected studies according to the NIV protocol. Because it may be difficult to exclude cardiogenic pulmonary edema in subjects with acute hypoxemic respiratory failure, ${ }^{22}$ we searched trials in which treatment with NIV was randomized for acute respiratory failure. The query was performed with the objective to obtain the highest sensitivity for detecting rele-

\section{QUICK LOOK}

\section{Current knowledge}

The use of noninvasive ventilation (NIV) is debated in de novo acute respiratory failure. It has been suggested that recent negative randomized controlled trials in the field were limited due to insufficient length of NIV application. However, whether prolonged NIV sessions are associated with lower intubation rates versus shorter sessions is unknown.

\section{What this paper contributes to our knowledge}

Based on this systematic review of randomized controlled trials of NIV for de novo acute respiratory failure, prolonged NIV sessions were not associated with lower intubation rates compared with shorter sessions. Similarly, the use of dedicated NIV ventilators was not associated with lower intubation rates versus ICU ventilators. However, studies in which the PEEP levels were $>6 \mathrm{~cm} \mathrm{H}_{2} \mathrm{O}$, the intubation rates were significantly lower than in studies with lower PEEP levels.

vant trials, including those with only subgroups of subjects with de novo respiratory failure, whereas the human screening ensured high specificity. The study was registered in the PROSPERO database (CRD42018095087) and adheres to the PRISMA (Preferred Reporting Items for Systematic reviews and Meta-Analyses) checklist. ${ }^{23}$ We searched in Medline and Embase for relevant studies in English, Spanish, or French by using the following search words: "acute, noninvasive ventilation, positive pressure respiration, random*, trial." Relevant studies were selected independently by 2 of us (MAH, RC). Conflicting entries were discussed with a third author (AWT) and resolved by consensus.

\section{Study Selection and Data Collection Process}

After removal of duplicates, the abstracts were screened independently by 2 of us (MAH, RC) to exclude physiologic studies that were not about NIV, those in which NIV was not randomized or were in a pediatric population, and those performed outside of ICUs. Then, based on full-text analysis, we excluded trials that randomized NIV for invasive procedures, trauma, asthma, postextubation respiratory failure, postoperative respiratory failure, cardiogenic pulmonary edema, acute-on-chronic respiratory failure, and patients with do-not-intubate orders. As a consequence, studies that included subjects with de novo respiratory failure and that mixing different types of acute respiratory failure were retained in the qualitative synthesis. For trials that included mixed populations (ie, subjects who were 
hypoxemic with de novo respiratory failure, and subjects who were hypercapnic with acute-on-chronic respiratory failure), the results sections were carefully read to extract specific outcomes on subjects with de novo respiratory failure, to exclude those with chronic lung disease. If specific outcomes of subjects with de novo respiratory failure could not be identified, then the study was excluded. Similarly, we extracted the protocol for applying NIV from the methods sections of the retained trials and excluded studies in which details on this protocol could not be identified based on the full-text analysis. This selection enabled us to quantitatively analyze intubation rates in subjects admitted to ICU for de novo respiratory failure and treated with a specific NIV protocol.

\section{Data Collection Process and Items}

NIV sessions were arbitrarily considered prolonged when the first session lasted at least $6 \mathrm{~h}$; if not, then the session was labeled a short session. We collected information on the type of ventilator (dedicated NIV or ICU), humidification device (heat-and-moisture exchange filter or heated humidifier), interface (oronasal or nasal mask), mode of ventilation, and year of publication. We extracted the number of subjects, their characteristics (age, severity score at ICU admission, baseline breathing frequency, $\mathrm{P}_{\mathrm{aCO}}, \mathrm{P}_{\mathrm{aO}_{2}} / \mathrm{F}_{\mathrm{IO}_{2}}$ ), the characteristics of NIV treatment (actual NIV duration within the first $24 \mathrm{~h}$ after protocol start; NIV duration during ICU stay; initial NIV settings, including $\mathrm{F}_{\mathrm{IO}_{2}}$, pressure support, PEEP, expiratory tidal volume), and their outcomes (intubation rate, length of mechanical ventilation, ICU and hospital mortality, ICU and hospital length of stay). Data were expressed in mean $\pm \mathrm{SD}$.

\section{Statistical Analysis}

Original data expressed in median and quartiles or in median, minimum, and maximum values were converted into mean $\pm \mathrm{SD}$ according to Wan et al. ${ }^{24}$ For each trial, the intubation rate and $95 \%$ CI were reported. The mean intubation rate of each subgroup was calculated by using the inverse variance method. The proportion of total variation in the study estimate due to heterogeneity was described by using $\mathrm{I}^{2}$. When heterogeneity was significant $\left(\mathrm{I}^{2}>30 \%\right)$, the subgroups were compared by using a random effects model, otherwise, a fixed effects model was used. A $P$ value $<.05$ was considered significant. Analyses were conducted by using R software (https://rproject.org/. Accessed October 25, 2018).

\section{Results}

\section{Study Selection}

Of the 858 studies identified from the search, 758 were excluded for the following reasons: 360 were not about NIV, 152 did not randomize NIV, 144 were performed outside of ICUs, 99 were physiologic studies, 2 were on a pediatric population, and 1 full-text article was not found. From the 100 full-text articles screened, 80 were excluded because of the focus on acute-on-chronic respiratory failure (22), postoperative respiratory failure (19), postextubation respiratory failure (17), cardiogenic pulmonary edema (14), invasive procedures (4), asthma (2), trauma (1), or included subjects with a do-not-intubate order (1). Consequently, 20 studies were included in the qualitative synthesis. Among these, 3 were excluded because specific data on subjects with de novo respiratory failure could not be extracted and 3 were excluded because the NIV protocol was not specified in the methods section (Fig. 1). Among the 14 studies $^{5,7,8,9,11,13,14,22,25-30}$ retained in the qualitative analysis, 2 mixed different types of respiratory failure but provided specific outcomes on subjects with de novo respiratory failure. 9,11 Therefore, 750 subjects were retained in the quantitative analysis.

\section{Study Characteristics}

The characteristics of the studies analyzed are displayed in Table 1. The subjects were included because of high breathing frequency in 11 studies $5,8,9,11,13,25-30(79 \%)$, low $\mathrm{P}_{\mathrm{aO}_{2}} / \mathrm{F}_{\mathrm{IO}_{2}}$ in 11 studies $5,8,9,11,14,24,25,26,27,28,30$ (79\%), and pulmonary infiltrates on chest radiographs in 3 studies $^{14,22,25}$ (21\%). Thresholds for each inclusion criterion varied among all the studies. Only 2 studies ${ }^{8,13}(14 \%)$ considered $\mathrm{P}_{a C O}$ as an inclusion criterion (Table 1): in the trial from Frat et al, ${ }^{8}$ a $\mathrm{P}_{\mathrm{aCO}_{2}} \leq 45 \mathrm{~mm} \mathrm{Hg}$ was a mandatory criterion, whereas, in the study from Wysocki et al, ${ }^{13} \mathrm{a} \mathrm{P}_{\mathrm{aCO}_{2}} \geq 50 \mathrm{~mm} \mathrm{Hg}$ was a possible but not mandatory inclusion criterion. NIV was applied during prolonged sessions in 10 studies $^{5,7,9,11,13,14,22,27,28,29}(319$ subjects [43\%]) and during short sessions in 4 studies $8,25,26,28$ (431 subjects [57\%]). The various NIV protocols are displayed in Supplementary Table 1 (see the supplementary materials at http://www. rcjournal.com). A dedicated NIV ventilator was used in 6 studies $7,8,11,14,28,29$ (157 subjects [21\%]). Half of the studies were multi-center ${ }^{7,8,9,14,22,26,30}$ (550 subjects [73\%]). All the studies except one used a bi-level positive-pressure ventilation mode 22 and an oronasal mask, ${ }^{11}$ and applied prespecified intubation criteria ${ }^{11}$ (see details in Supplementary Table 2 [see the supplementary materials at http:// www.rcjournal.com]). Only 3 studies reported the type of humidification device. $22,26,27$ 


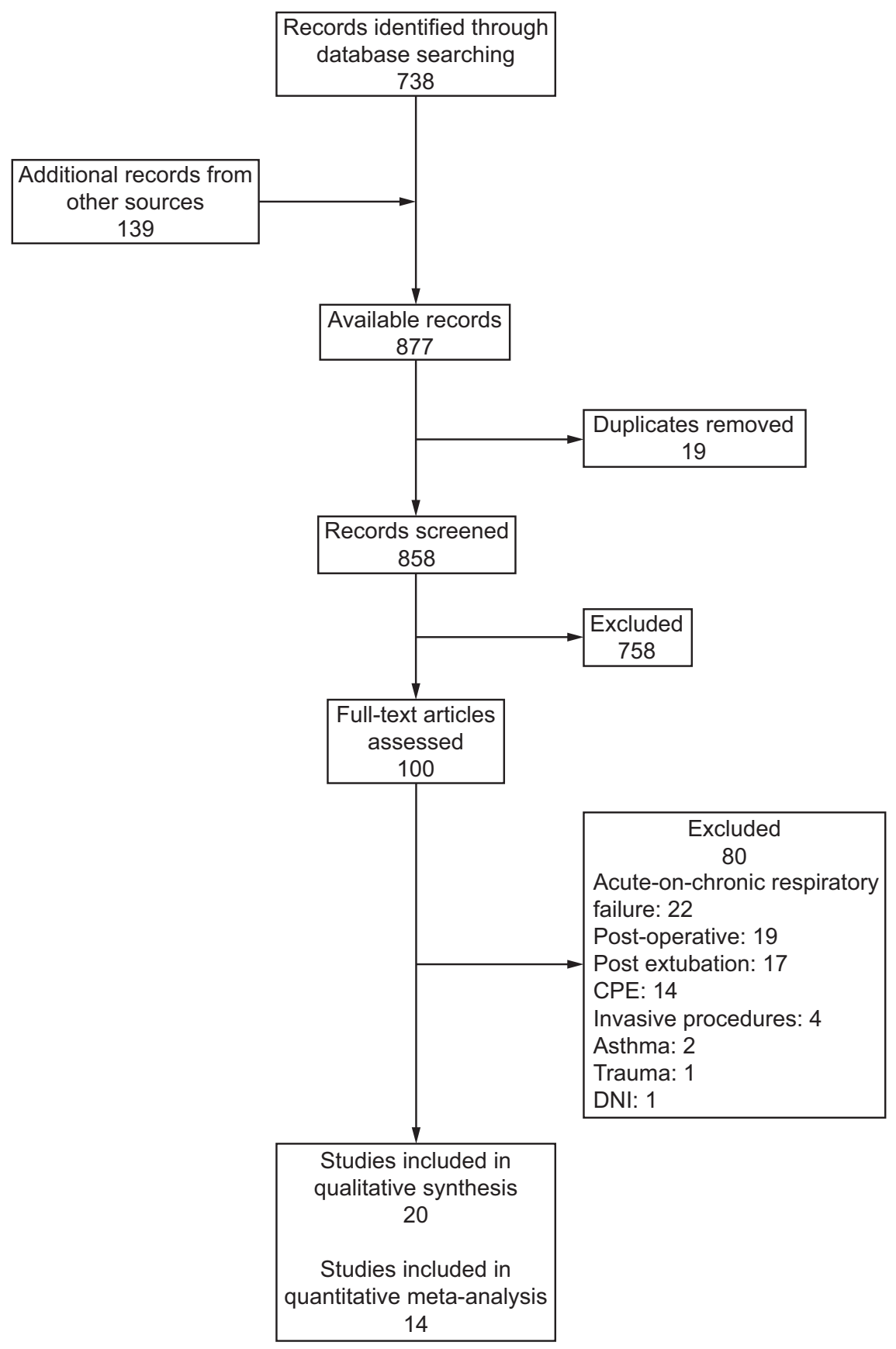

Fig. 1. Flow chart. $\mathrm{CPE}=$ cardiogenic pulmonary edema, $\mathrm{DNI}=$ do not intubate.

Details of the 750 subjects included in the systematic review are displayed in Supplementary Table 3 (see the supplementary materials at http://www.rcjournal.com). The breathing frequency at inclusion was $35 \pm 6$ breaths/min, $\mathrm{P}_{\mathrm{aCO}_{2}}$ was $38 \pm 9 \mathrm{~mm} \mathrm{Hg}$, and $\mathrm{P}_{\mathrm{aO}_{2}} / \mathrm{F}_{\mathrm{IO}_{2}}$ was $152 \pm 49 \mathrm{~mm} \mathrm{Hg}$. The mean \pm SD PEEP was $6 \pm 1 \mathrm{~cm} \mathrm{H}_{2} \mathrm{O}$ and was reported in 9 studies $5,7,8,13,14,22,25-27$ (64\%). The mean \pm SD pressure support level reported in 7 studies $^{7,8,13,14,22,27,28}(50 \%)$ was $10 \pm 2 \mathrm{~cm} \mathrm{H}_{2} \mathrm{O}$, whereas the mean \pm SD expired tidal volume available in 2 studies $^{8,30}$ was $9.2 \pm 3.1 \mathrm{~mL} / \mathrm{kg}$ of predicted body weight. The actual NIV duration within the first $24 \mathrm{~h}$ was reported in 5 studies $14,8,22,25,28(36 \%)$, whereas $\mathrm{F}_{\mathrm{IO}_{2}}$ was reported in only 4 studies $7,8,13,26(29 \%)$. The main cause of respiratory failure was reported in 11 of the 14 studies $^{5,7,8,13,14,22,25,26,27,29,30}$ (672 subjects [90\%]) (Supplementary Table 4 [see the supplementary materials at http://www.rcjournal.com]). Pneumonia accounted for $60 \%$ of the cases (399 subjects). The cause of respiratory failure differed significantly between the subjects treated with prolonged or shorter NIV sessions $(P<.001)$. 


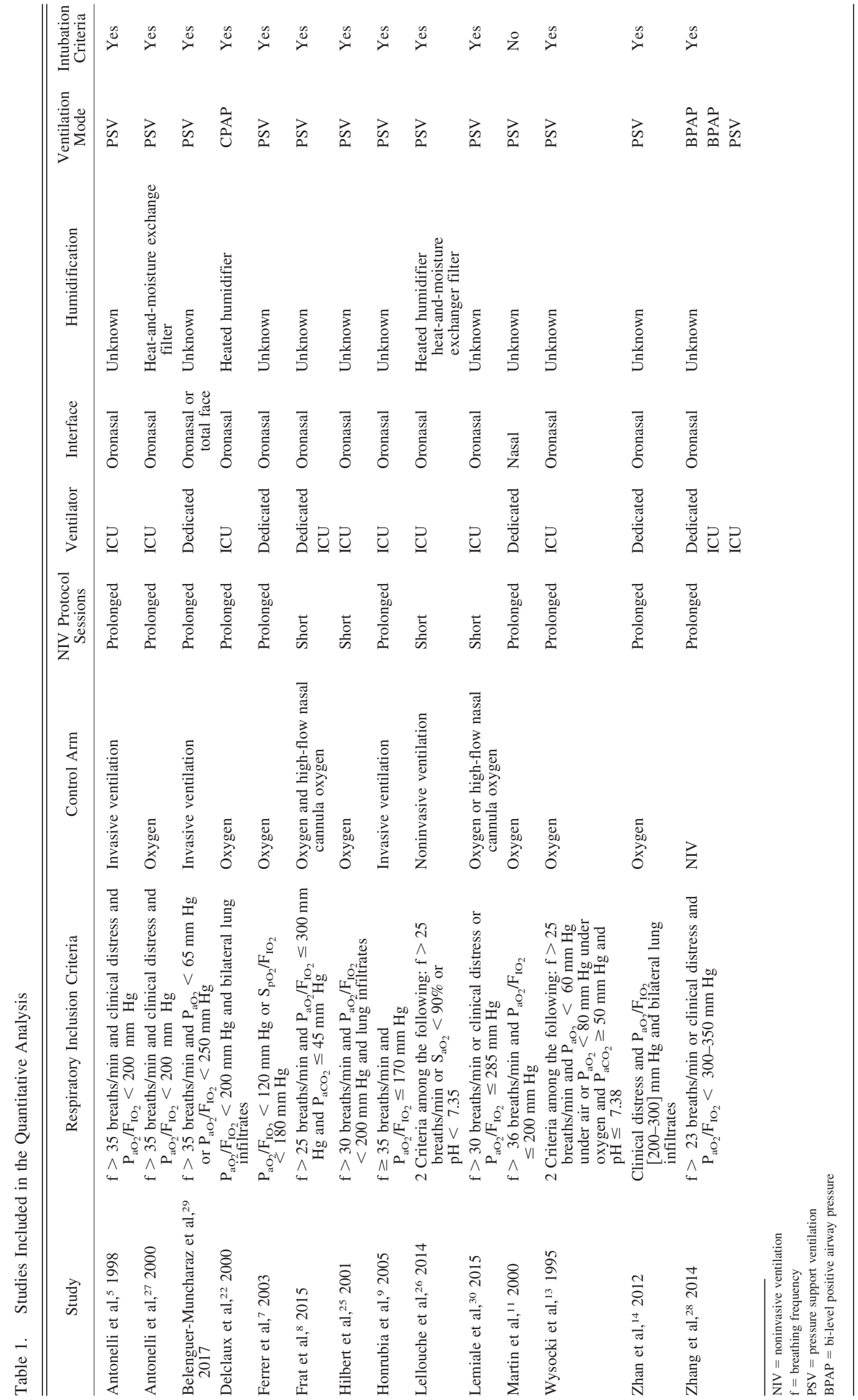




\section{NIV Protocol and Intubation in De Novo Respiratory Failure}

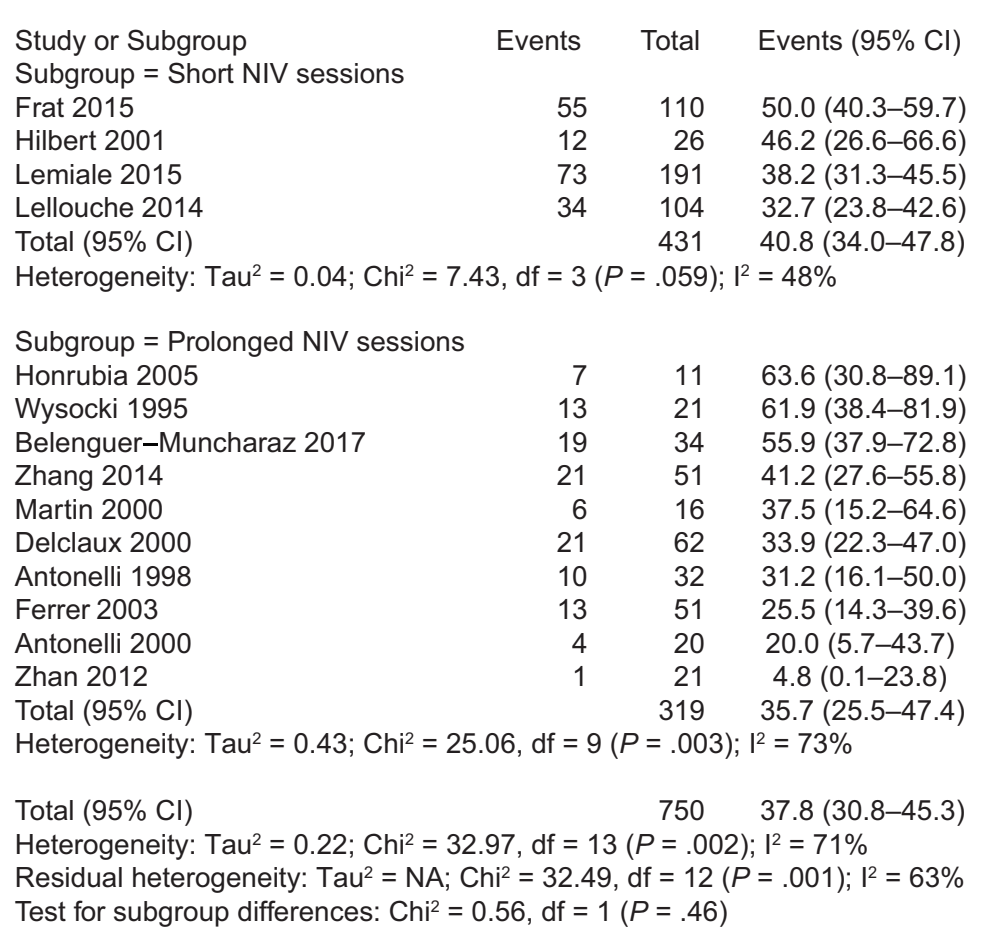

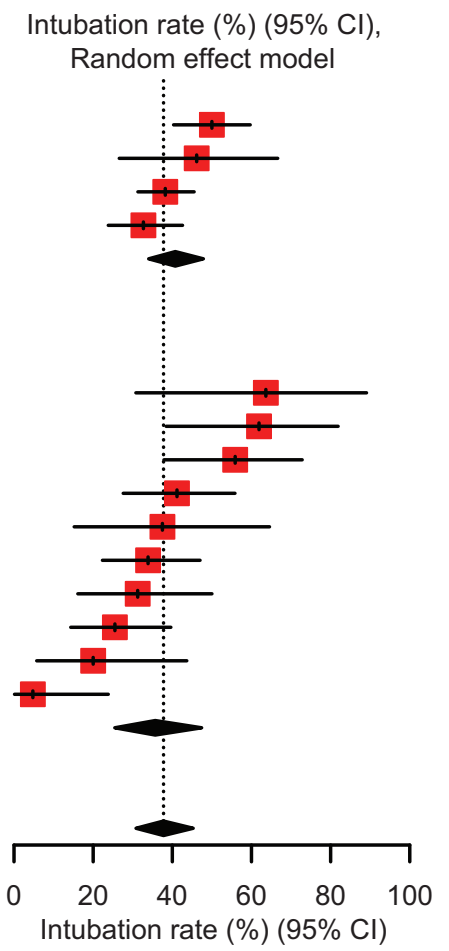

Fig. 2. Forest plot comparing the incidence of intubation rates in subjects with de novo acute hypoxemic respiratory failure treated with prolonged or shorter NIV sessions of noninvasive ventilation.

The outcome of subjects included are displayed in Supplementary Table 5 (see the supplementary materials at http://www.rcjournal.com). The overall intubation rate was $39 \%$ (289 of 750 subjects) and ICU mortality was $23 \%$ (160 of 699 subjects). Time to intubation was reported in only 5 studies, , ,8,13,25,27 whereas NIV duration $7,13,14,25-27$ and mortality of subjects who were intubated $5,8,14,25,27,29,30$ were reported in 6 and 7 studies, respectively.

\section{Outcomes}

Intubation rates did not differ between the subjects treated with prolonged NIV versus those treated with shorter NIV sessions $(36 \%, 95 \%$ CI $26-47 \%$ vs $41 \%$, 95\% CI $34-$ $48 \%$, respectively; $P=.46$ ) (Fig. 2). Likewise, intubation rates did not differ between studies that used dedicated NIV ventilators or ICU ventilators $(39 \%, 95 \%$ CI $24-$ $56 \%$ vs $40 \%, 95 \%$ CI $33-47 \%$, respectively; $P=.93$ ) (Fig. 3). Among the 9 studies specifying the set PEEP5,7,8,13,14,22,25-27 (including 447 of the 750 subjects [60\%]), use of higher PEEP levels $>6 \mathrm{~cm} \mathrm{H}_{2} \mathrm{O}$ was associated with lower intubation rates than lower PEEP levels $(25 \%, 95 \%$ CI $15-37 \%$ vs $43 \%$, $95 \%$ CI $33-54 \%$, respectively; $P=.03$ (Fig. 4). The heterogeneity among all the studies was significant, as illustrated by a funnel plot (Supplementary Fig. 1 [see the supplementary materials at http://www.rcjournal.com]). Similarly, heterogeneity be- tween studies and subgroups was significant in all analyses (Figs. 2 to 4 ).

\section{Discussion}

To our knowledge, this systematic review was the first to investigate the relationship between the NIV protocol and the incidence of NIV failure in subjects with de novo respiratory failure. Prolonged NIV sessions and the use of dedicated NIV ventilators did not influence the incidence of intubation among the randomized controlled trials analyzed. The only variable that influenced the primary outcome variable was the use of a higher PEEP, which was associated with fewer intubations compared with a lower PEEP. Also, all the trials had different inclusion criteria, and there were large amounts of outcome data missing after NIV application (such as expired tidal volume, time to intubation, or mortality of patients who were intubated).

The inclusion criteria that defined de novo respiratory failure were particularly heterogeneous from one study to another. Thresholds of the breathing frequency ranged from 23 to 35 breaths/min. ${ }^{5,27-29}$ However, the mean breathing frequency at inclusion was $\geq 30$ breaths/min in all studies but one. ${ }^{30}$ Similarly, the criterion for hypoxemia on inclusion was highly variable among the studies, which resulted in a range of $\mathrm{P}_{\mathrm{aO}_{2}} / \mathrm{F}_{\mathrm{IO}_{2}}$ from $100 \mathrm{~mm} \mathrm{Hg} 29$ to $225 \mathrm{~mm} \mathrm{Hg} .{ }^{14}$ However, the mean $\mathrm{P}_{\mathrm{aO}_{2}} / \mathrm{F}_{\mathrm{IO}_{2}}$ on inclusion was $<200 \mathrm{~mm}$ 


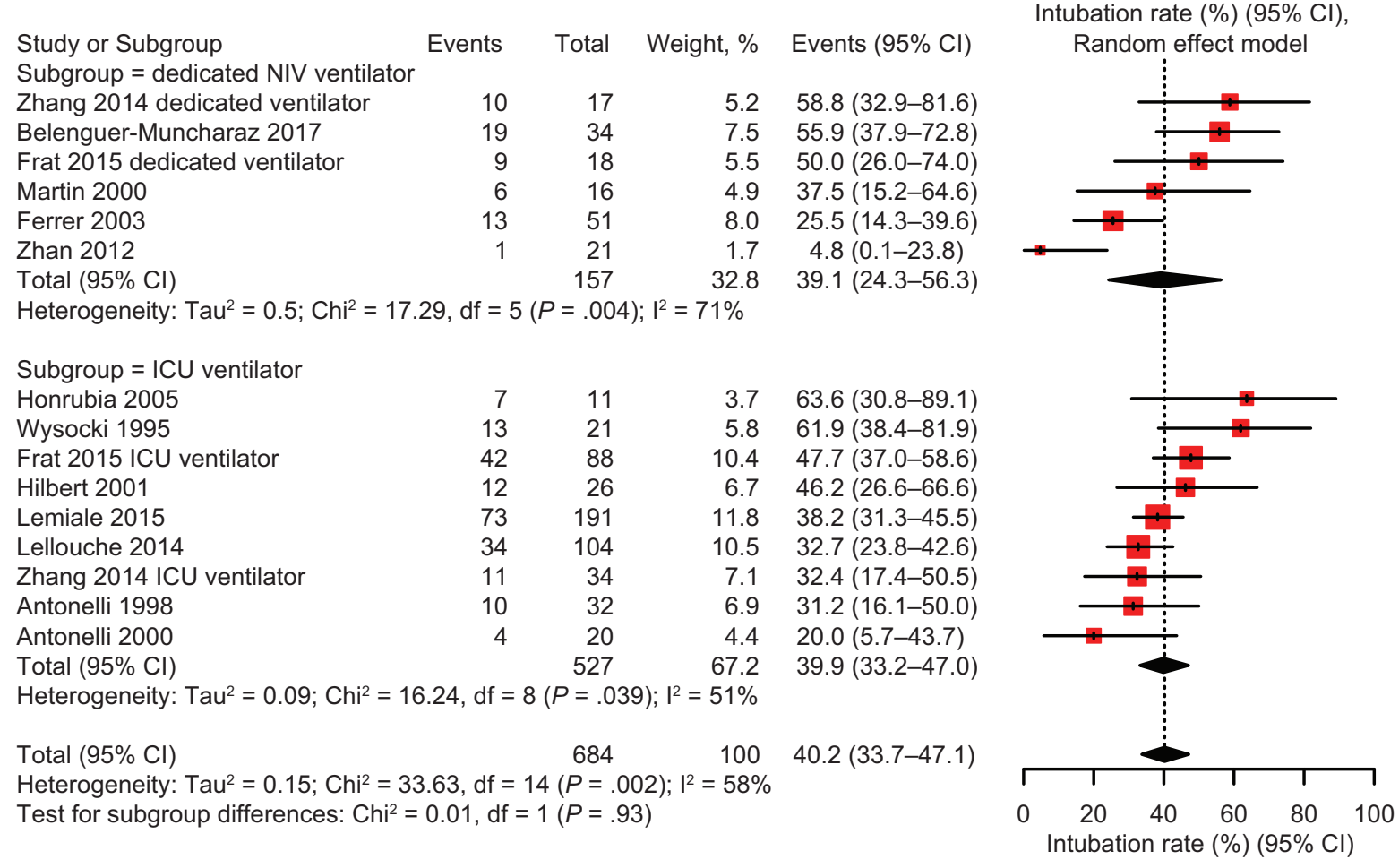

Fig. 3. Forest plot comparing the incidence of intubation rates in subjects with de novo acute hypoxemic respiratory failure treated with noninvasive ventilation using a dedicated or an intensive care unit ventilator.

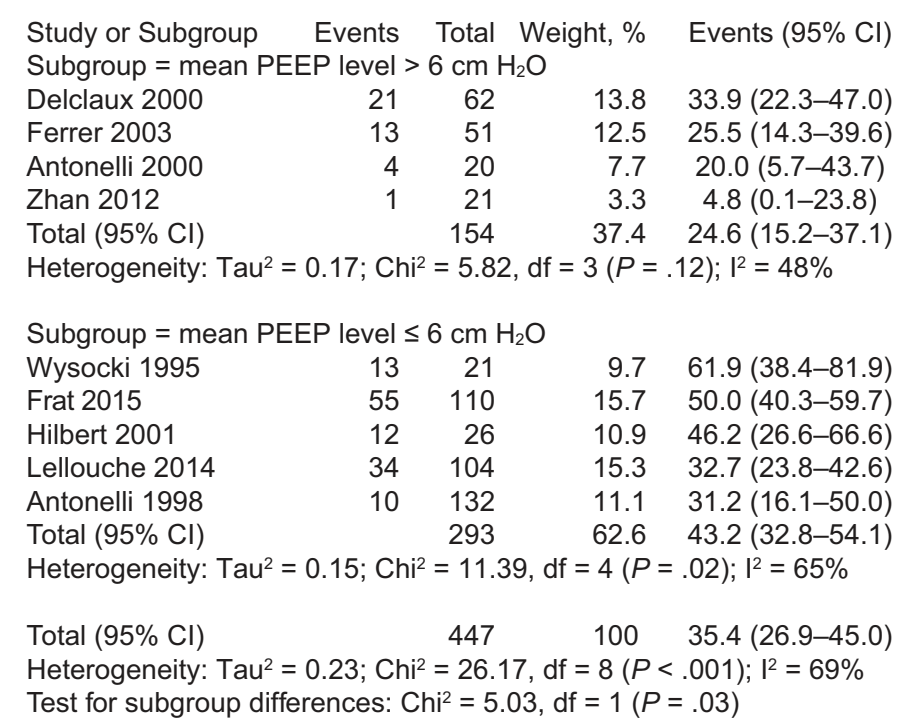

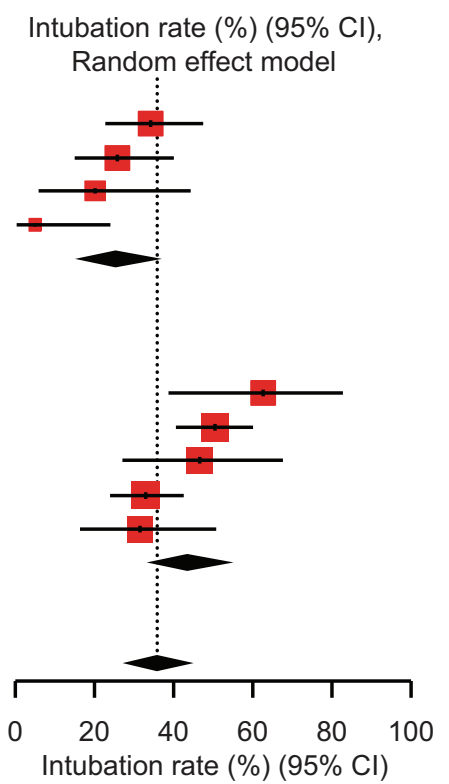

Fig. 4. Forest plot comparing the incidence of intubation rates in subjects with de novo acute hypoxemic respiratory failure treated with noninvasive ventilation using high or low PEEP.

$\mathrm{Hg}$ in 10 of 12 studies $5,7,8,13,14,22,25-30$ in which $\mathrm{P}_{\mathrm{aO}_{2}} / \mathrm{F}_{\mathrm{IO}_{2}}$ could be extracted (681 subjects). Only a low proportion of studies required pulmonary infiltrates as an inclusion criterion. As a consequence, the proportion of subjects with ARDS according to the Berlin definition ${ }^{31}$ could mark- edly differ from one trial to the next. Likewise, some subjects were hypercarbic and may have exhibited respiratory muscle fatigue. Thus, the inclusion of subjects with a wide range of $\mathrm{P}_{\mathrm{aCO}}$ illustrated different severity levels of respiratory failure, which likely contributed to the hetero- 


\section{NIV Protocol and Intubation in De Novo Respiratory Failure}

geneity among the studies. Overall, these varying inclusion criteria may explain the heterogeneity of intubation rates, which ranged from 5 to $64 \%$. An individual analysis in more-homogeneous subgroups might reduce heterogeneity among studies and possibly among intubation rates.

High PEEP levels were associated with fewer intubations compared with lower PEEP levels. Although findings should be interpreted cautiously given that PEEP levels were reported in only 95,7,8,13,14,22,25-27 of the 14 studies (60\% of the subjects), the beneficial effects of high PEEP levels on oxygenation were suggested in a previous physiologic study. ${ }^{17}$ Similarly, in subjects with ARDS and who were on invasive ventilation, the high PEEP levels were associated with shorter duration of mechanical ventilation and lower mortality than low PEEP levels. ${ }^{18}$ In a recent study, subjects with ARDS treated with a helmet had markedly lower intubation rates than those treated with a oronasal mask. ${ }^{32}$ Although the helmet use may explain this difference in terms of improved patient comfort, those treated with a helmet also had higher PEEP levels than those treated with a oronasal mask, a factor that might help to explain beneficial effects. ${ }^{32}$

In contrast, the use of prolonged rather than shorter NIV sessions to reduce patient self-inflicted lung injury ${ }^{33}$ and, consequently, intubation rates was not supported by our results. From a physiologic perspective, the concept of patient self-inflicted lung injury has been described in animal models invasively ventilated when using pressurecontrolled ventilation without interruption and not treated with NIV. ${ }^{34,35}$ Moreover, 2 clinical studies reported deleterious effects of large tidal volumes on intubation rates during NIV, unrelated to the duration of the NIV session. ${ }^{36,37}$ Consequently, there is no strong physiologic rationale in suggesting the use of prolonged over shorter NIV sessions to decrease patient self-inflicted lung injury. From a clinical perspective, 2 recent large multi-center trials reported no benefit from short NIV sessions compared with oxygen therapy ${ }^{8,30}$ It has been pointed out that these negative results could have been due to the NIV protocol and that use of prolonged NIV sessions may have been associated with better outcomes. ${ }^{38,39}$ However, our analysis, which focused on 750 subjects, did not highlight any potential benefit of prolonged NIV sessions in de novo respiratory failure. Likewise, the type of ventilator did not seem to influence NIV success rates. Although dedicated NIV ventilators may promote patient-ventilator synchrony and tolerance, the amount of major patient-ventilator asynchrony differed little between NIV ventilators and ICU ventilators with the NIV algorithm engaged. ${ }^{16}$ Therefore, our results did not suggest the need for a dedicated NIV ventilator to optimize NIV in de novo respiratory failure.

Unfortunately, most of the studies did not report crucial information concerning their NIV protocol. Although the deleterious role of large expired tidal volumes was re- ported nearly 2 decades ago in subjects with ARDS on invasive ventilation, ${ }^{40}$ only $2^{8,30}$ of the 14 trials we analyzed (14\%) reported expired tidal volumes. However, 2 recent studies reported that large expired tidal volumes were associated with higher NIV failure rates, which suggested potentially harmful effects of NIV. ${ }^{36,37}$ Time to intubation was reported in only $36 \%$ of the trials, even though delayed intubation may also have had an impact on outcomes. ${ }^{41}$ Moreover, use of prolonged NIV sessions might influence the time to intubation. Because time to intubation and expired tidal volume may directly influence outcomes of patients who were intubated by generating patient self-inflicted lung injury,,$^{33}$ we believe that the abovementioned data should be given in future trials on NIV for de novo respiratory failure. Likewise, to better investigate the potential harmfulness of NIV, we believe that mortality of patients who were intubated, which was reported in only half of the studies, should be systematically reported.

\section{Limitations}

Several limitations have to be acknowledged. First, the studies included were heterogeneous. However, we exclusively selected randomized trials performed in ICUs in which NIV was applied according to a precise protocol detailed in the methods section of each study. Moreover, statistical analysis was performed by using random-effect analysis according to the Cochrane collaboration. ${ }^{22} \mathrm{We}$ believe that the differences in outcomes could be explained by the heterogeneity in inclusion criteria, NIV protocols, causes of respiratory failure, and intubation criteria, as discussed above. Second, our definition of a prolonged NIV session, continuous NIV for at least $6 \mathrm{~h}$, is debatable. Indeed, in almost all of the studies, NIV application was not "continuous until intubation or weaning" per se and, for instance, could be interrupted several times a day to test oxygenation status or to clear secretions.

However, all the trials assigned in the prolonged application group had a first NIV session of at least $6 \mathrm{~h}$. Therefore, it could be argued that our study compared the intubation rates according to the duration of the first NIV session $\geq$ or $<6 \mathrm{~h}$ ) and that none of the included studies had optimal NIV duration. Third, we included trials in which some subjects may have had cardiogenic pulmonary edema. In fact, it may be difficult to identify cardiogenic pulmonary edema in patients with acute respiratory failure. ${ }^{22}$ Moreover, studies on overt cardiogenic pulmonary edema were excluded, which, therefore, limited this bias. Fourth, 3 trials were excluded for missing data on the NIV protocol. For one study, the authors were contacted but did not answer our e-mail. ${ }^{32}$ The 2 other articles included 7 and 32 subjects, respectively, and only data from abstracts were available. ${ }^{42,43}$ Given the small sample size of these studies, their inclusion would probably not have influ- 


\section{NIV Protocol and Intubation in De Novo Respiratory Failure}

enced our findings. Fifth, the definition of prolonged NIV sessions was arbitrary, and a different NIV duration of NIV might have led to different results. However, there is no consensus definition for prolonged NIV sessions. Moreover, whether NIV application was in keeping with study protocols is unknown.

\section{Conclusions}

Our systematic review of trials on NIV for de novo respiratory failure in the ICU suggested that higher PEEP levels could reduce NIV failure rates. In contrast, prolonged NIV sessions within the first $6 \mathrm{~h}$ or use of dedicated NIV ventilators were not associated with better outcomes. The variability of inclusion criteria and the lack of important data may explain the heterogeneity in intubation rates observed. We believe that a consensual definition of de novo respiratory failure and guidelines on data to provide in trials on NIV could help to better understand benefits or harm of NIV in this clinical setting.

\section{ACKNOWLEDGMENT}

We thank Jeffrey Arsham for editing the original manuscript.

\section{REFERENCES}

1. Demoule A, Chevret S, Carlucci A, Kouatchet A, Jaber S, Meziani F, et al.; oVNI Study Group, REVA Network (Research Network in Mechanical Ventilation Changing use of noninvasive ventilation in critically ill patients: trends over 15 years in francophone countries. Intensive Care Med 2016;42(1):82-92.

2. Weng CL, Zhao YT, Liu QH, Fu CJ, Sun F, Ma YL, et al. Metaanalysis: noninvasive ventilation in acute cardiogenic pulmonary edema. Ann Intern Med 2010;152(9):590-600.

3. Osadnik CR, Tee VS, Carson-Chahhoud KV, Picot J, Wedzicha JA, Smith BJ. Non-invasive ventilation for the management of acute hypercapnic respiratory failure due to exacerbation of chronic obstructive pulmonary disease. Cochrane Database Syst Rev 2017;7: CD004104.

4. Rochwerg B, Brochard L, Elliott MW, Hess D, Hill NS, Nava S, et al. Official ERS/ATS clinical practice guidelines: noninvasive ventilation for acute respiratory failure. Eur Respir J 2017;50(2). pii: 1602426.

5. Antonelli M, Conti G, Rocco M, Bufi M, De Blasi RA, Vivino G, et al. A comparison of noninvasive positive-pressure ventilation and conventional mechanical ventilation in patients with acute respiratory failure. N Engl J Med 1998;339(7):429-435.

6. Confalonieri M, Potena A, Carbone G, Porta RD, Tolley EA, Umberto Meduri G. Acute respiratory failure in patients with severe community-acquired pneumonia. A prospective randomized evaluation of noninvasive ventilation. Am J Respir Crit Care Med 1999; 160(5 Pt 1):1585-1591.

7. Ferrer M, Esquinas A, Leon M, Gonzalez G, Alarcon A, Torres A. Noninvasive ventilation in severe hypoxemic respiratory failure: a randomized clinical trial. Am J Respir Crit Care Med 2003;168(12): 1438-1444.

8. Frat JP, Thille AW, Mercat A, Girault C, Ragot S, Perbet S, et al.; FLORALI Study Group, REVA Network. High-flow oxygen through nasal cannula in acute hypoxemic respiratory failure. $\mathrm{N}$ Engl $\mathrm{J}$ Med 2015;372(23):2185-2196.

9. Honrubia T, Garcia López FJ, Franco N, Mas M, Guevara M, Daguerre $\mathrm{M}$, et al. Noninvasive vs conventional mechanical ventilation in acute respiratory failure: a multicenter, randomized controlled trial. Chest 2005;128(6):3916-3924.

10. Kramer N, Meyer TJ, Meharg J, Cece RD, Hill NS. Randomized, prospective trial of noninvasive positive pressure ventilation in acute respiratory failure. Am J Respir Crit Care Med 1995;151(6):17991806.

11. Martin TJ, Hovis JD, Costantino JP, Bierman MI, Donahoe MP, Rogers RM, et al. A randomized, prospective evaluation of noninvasive ventilation for acute respiratory failure. Am J Respir Crit Care Med 2000;161(3 Pt 1):807-813.

12. Wood KA, Lewis L, Von Harz B, Kollef MH. The use of noninvasive positive pressure ventilation in the emergency department: results of a randomized clinical trial. Chest 1998;113(5):1339-1346.

13. Wysocki M, Tric L, Wolff MA, Millet H, Herman B. Noninvasive pressure support ventilation in patients with acute respiratory failure. A randomized comparison with conventional therapy. Chest 1995; 107(3):761-768.

14. Zhan Q, Sun B, Liang L, Yan X, Zhang L, Yang J, et al. Early use of noninvasive positive pressure ventilation for acute lung injury: a multicenter randomized controlled trial. Crit Care Med 2012;40(2): 455-460.

15. Nava S, Navalesi P, Conti G. Time of non-invasive ventilation. Intensive Care Med 2006;32(3):361-370.

16. Carteaux G, Lyazidi A, Cordoba-Izquierdo A, Vignaux L, Jolliet P, Thille AW, et al. Patient-ventilator asynchrony during noninvasive ventilation: a bench and clinical study. Chest 2012;142(2):367-376.

17. L'Her E, Deye N, Lellouche F, Taille S, Demoule A, Fraticelli A, et al. Physiologic effects of noninvasive ventilation during acute lung injury. Am J Respir Crit Care Med 2005;172(9):1112-1118.

18. Briel M, Meade M, Mercat A, Brower RG, Talmor D, Walter SD, et al. Higher vs lower positive end-expiratory pressure in patients with acute lung injury and acute respiratory distress syndrome: systematic review and meta-analysis. JAMA 2010;303(9):865-873.

19. Xu XP, Zhang XC, Hu SL, Xu JY, Xie JF, Liu SQ, et al. Noninvasive ventilation in acute hypoxemic nonhypercapnic respiratory failure: a systematic review and meta-analysis. Crit Care Med 2017; 45(7):e727-e733.

20. Huang HB, Xu B, Liu GY, Lin JD, Du B. Use of noninvasive ventilation in immunocompromised patients with acute respiratory failure: a systematic review and meta-analysis. Crit Care 2017;21(1):4.

21. Kondo Y, Kumasawa J, Kawaguchi A, Seo R, Nango E, Hashimoto $\mathrm{S}$. Effects of non-invasive ventilation in patients with acute respiratory failure excluding post-extubation respiratory failure, cardiogenic pulmonary edema and exacerbation of COPD: a systematic review and meta-analysis. J Anesth 2017;31(5):714-725.

22. Delclaux C, L'Her E, Alberti C, Mancebo J, Abroug F, Conti G, et al. Treatment of acute hypoxemic nonhypercapnic respiratory insufficiency with continuous positive airway pressure delivered by a face mask: a randomized controlled trial. JAMA 2000;284(18):23522360.

23. Liberati A, Altman DG, Tetzlaff J, Mulrow C, Gotzsche PC, Ioannidis JP, et al. The PRISMA statement for reporting systematic reviews and meta-analyses of studies that evaluate healthcare interventions: explanation and elaboration. BMJ 2009;339:b2700.

24. Wan X, Wang W, Liu J, Tong T. Estimating the sample mean and standard deviation from the sample size, median, range and/or interquartile range. BMC Med Res Methodol 2014;14:135.

25. Hilbert G, Gruson D, Vargas F, Valentino R, Gbikpi-Benissan G, Dupon M, et al. Noninvasive ventilation in immunosuppressed pa- 


\section{NIV Protocol and Intubation in De Novo Respiratory Failure}

tients with pulmonary infiltrates, fever, and acute respiratory failure. N Engl J Med. 2001;344(7):481-487.

26. Lellouche F, L'Her E, Abroug F, Deye N, Rodriguez PO, Rabbat A, et al. Impact of the humidification device on intubation rate during noninvasive ventilation with ICU ventilators: results of a multicenter randomized controlled trial. Intensive Care Med. 2014;40(2):211219.

27. Antonelli M, Conti G, Bufi M, Costa MG, Lappa A, Rocco M, et al. Noninvasive ventilation for treatment of acute respiratory failure in patients undergoing solid organ transplantation: a randomized trial. JAMA 2000;283(2):235-241.

28. Zhang J, Cao J, Feng J, Wu Q, Chen BY. A study of noninvasive positive-pressure mechanical ventilation in the treatment of acute lung injury with a complex critical care ventilator. J Int Med Res 2014;42(3):788-798.

29. Belenguer-Muncharaz A, Cubedo-Bort M, Blasco-Asensio D, Mateu-Campos L, Vidal-Tegedor B, Madero-Pérez J, et al. Non-invasive ventilation versus invasive mechanical ventilation in patients with hypoxemic acute respiratory failure in an intensive care unit. A randomized controlled study. Minerva Pneumol 2017;56(1):1-10.

30. Lemiale V, Mokart D, Resche-Rigon M, Pène F, Mayaux J, Faucher E, et al.; Groupe de Recherche en Réanimation Respiratoire du patient d'Onco-Hématologie (GRRR-OH). Effect of noninvasive ventilation vs oxygen therapy on mortality among immunocompromised patients with acute respiratory failure: a randomized clinical trial. JAMA 2015;314(16):1711-1719.

31. ARDS Definition Task Force, Ranieri VM, Rubenfeld GD, Thompson BT, Ferguson ND, Caldwell E, et al. Acute respiratory distress syndrome: the Berlin Definition. JAMA 2012;307(23):2526-2533.

32. Patel BK, Wolfe KS, Pohlman AS, Hall JB, Kress JP. effect of noninvasive ventilation delivered by helmet vs face mask on the rate of endotracheal intubation in patients with acute respiratory distress syndrome: a randomized clinical trial. JAMA 2016;315(22):24352441.

33. Brochard L, Slutsky A, Pesenti A. Mechanical ventilation to minimize progression of lung injury in acute respiratory failure. Am J Respir Crit Care Med 2017;195(4):438-442.
34. Yoshida T, Uchiyama A, Matsuura N, Mashimo T, Fujino Y. Spontaneous breathing during lung-protective ventilation in an experimental acute lung injury model: high transpulmonary pressure associated with strong spontaneous breathing effort may worsen lung injury. Crit Care Med 2012;40(5):1578-1585.

35. Yoshida T, Uchiyama A, Matsuura N, Mashimo T, Fujino Y. The comparison of spontaneous breathing and muscle paralysis in two different severities of experimental lung injury. Crit Care Med 2013; 41(2):536-545.

36. Carteaux G, Millán-Guilarte T, De Prost N, Razazi K, Abid S, Thille $\mathrm{AW}$, et al. Failure of noninvasive ventilation for de novo acute hypoxemic respiratory failure: role of tidal volume. Crit Care Med 2016;44(2):282-290

37. Frat JP, Ragot S, Coudroy R, Constantin JM, Girault C, Prat G, et al.; REVA network. Predictors of intubation in patients with acute hypoxemic respiratory failure treated with a noninvasive oxygenation strategy. Crit Care Med 2018;46(2):208-215.

38. Sehgal IS, Dhooria S, Agarwal R. High-flow nasal cannula oxygen in respiratory failure. N Engl J Med 2015;373(14):1374.

39. Navalesi P, Gregoretti C, Antonelli M. Noninvasive ventilation and outcomes among immunocompromised patients. JAMA 2016; 315(17):1902.

40. Brower RG, Lanken PN, MacIntyre N, Matthay MA, Morris A, Ancukiewicz M, et al.; National Heart, Lung, and Blood Institute ARDS Clinical Trials Network. Higher versus lower positive endexpiratory pressures in patients with the acute respiratory distress syndrome. N Engl J Med 2004;351(4):327-336.

41. Esteban A, Frutos-Vivar F, Ferguson ND, Arabi Y, Apezteguía C, González M, et al. Noninvasive positive-pressure ventilation for respiratory failure after extubation. N Engl J Med 2004;350(24):24522460.

42. Azevedo JR, Montenegro WS, Leitao AL, Silva MM, Prazeres JS, Maranhao LP. High flow nasal cannula oxygen (HFNC) versus noninvasive positive pressure ventilation (NIPPV) in acute hypoxemic respiratory failure. A pilot randomized controlled trial. Intensive Care Med Exp 2015;3:A166 (Abstract).

43. Raine R. Noninvasive ventilation in acute respiratory failure. Criti Care 2000;:5179 (Abstract). 